\title{
JCDB: a comprehensive knowledge base for Jatropha curcas, an emerging model for woody energy plants
}

\author{
Xuan Zhang ${ }^{1,2+}$, Bang-Zhen Pan ${ }^{1,3+}$, Maosheng Chen ${ }^{1,3}$, Wen Chen ${ }^{1}$, Jing Li $i^{1,3}$, Zeng-Fu Xu ${ }^{1,3^{*}}$ and Changning Liu ${ }^{\text {* }^{*}}$ \\ From International Conference on Bioinformatics (InCoB 2019) \\ Jakarta, Indonesia. 10-12 September 2019
}

\begin{abstract}
Background: Jatropha curcas is an oil-bearing plant, and has seeds with high oil content ( $40 \%)$. Several advantages, such as easy genetic transformation and short generation duration, have led to the emergence of $J$. curcas as a model for woody energy plants. With the development of high-throughput sequencing, the genome of Jatropha curcas has been sequenced by different groups and a mass of transcriptome data was released. How to integrate and analyze these omics data is crucial for functional genomics research on J. curcas.

Results: By establishing pipelines for processing novel gene identification, gene function annotation, and gene network construction, we systematically integrated and analyzed a series of $J$. curcas transcriptome data. Based on these data, we constructed a J. curcas database (JCDB), which not only includes general gene information, gene functional annotation, gene interaction networks, and gene expression matrices but also provides tools for browsing, searching, and downloading data, as well as online BLAST, the JBrowse genome browser, ID conversion, heatmaps, and gene network analysis tools.

Conclusions: JCDB is the most comprehensive and well annotated knowledge base for J. curcas. We believe it will make a valuable contribution to the functional genomics study of $J$. curcas. The database is accessible at http://jcdb. liu-lab.com/.
\end{abstract}

Keywords: Jatropha curcas, Woody energy plant, Functional genomics, Database

\section{Background}

Jatropha curcas is a perennial shrub belonging to the Euphorbiaceae family. It is a tropical species that is native to Mexico and Central America and now thrives in Latin America, Africa, India, and South East Asia [1-5]. As a multi-functional plant, it has been used in traditional medicine and for hedges, animal feed, and firewood [6-9]. With the gradual depletion and cost escalation of fossil energy resources, J. curcas is now attracting much attention for its potential use for biofuel

\footnotetext{
* Correspondence: zfxu@xtbg.ac.cn; liuchangning@xtbg.ac.cn

${ }^{\dagger}$ Xuan Zhang and Bang-Zhen Pan contributed equally to this work.

${ }^{1}$ CAS Key Laboratory of Tropical Plant Resources and Sustainable Use,

Xishuangbanna Tropical Botanical Garden, The Innovative Academy of Seed

Design, Chinese Academy of Sciences, Menglun, Mengla, Yunnan 666303,

China

Full list of author information is available at the end of the article
}

production, because of its high seed oil content (the seeds of $J$. curcas contain $\sim 40 \%$ oil) [10], easy propagation, rapid growth, and ability to grow in a wide range of conditions, including degraded, sodic, alkaline, and contaminated soils $[7,11]$.

J. curcas has a relatively small genome, which is organized in 22 chromosomes (2n) [12]. The J. curcas genome has been sequenced by four groups worldwide [13-17]. For the RefSeq representative version from the $\mathrm{Wu}$ laboratory, the assembled genome is $320.5 \mathrm{Mb}$ [15]. J. curcas also has several advantages, including easy genetic transformation and short generation duration, which make it an attractive wood energy model plant for function genome analysis, particular among the Euphorbiaceae [18-20]. J. curcas is also a potential model for studies of flower sex determination in monoecious

(c) The Author(s). 2019 Open Access This article is distributed under the terms of the Creative Commons Attribution 4.0 International License (http://creativecommons.org/licenses/by/4.0/), which permits unrestricted use, distribution, and reproduction in any medium, provided you give appropriate credit to the original author(s) and the source, provide a link to the Creative Commons license, and indicate if changes were made. The Creative Commons Public Domain Dedication waiver (http://creativecommons.org/publicdomain/zero/1.0/) applies to the data made available in this article, unless otherwise stated. 
trees, as most $J$. curcas germplasms are monoecious, bearing male and female flowers on the same inflorescence $[21,22]$.

In recent years, there have been significant advances in the application of transcriptome analysis to J. curcas [22-31]. Using bioinformatics tools and a comprehensive knowledge database to integrate all these genome and transcriptome data is crucial for further functional genomics research on J. curcas. Advances in J. curcas research have led to the creation of several J. curcas genetic information resources. For instance, the Jatropha Genome Database (JAT_r4.5) focuses on the J. curcas genome sequence and annotation [13], and KaPPAView4 is a KEGG (Kyoto Encyclopedia of Genes and Genomes) pathway viewer for J. curcas [32]. Although each of these resources provides valuable information, there is a lack of database unification and integration of the $J$. curcas genome and transcriptome with a broad set of multi-omics analysis results, such as gene functional annotation, gene expression matrices, and gene interaction networks.

In this study, we constructed a J. curcas database (JCDB) that is dedicated to providing a comprehensive platform for $J$. curcas functional genomics research. By establishing pipelines for processing novel gene identification, gene function annotation, gene expression level quantification, and gene network construction, we systematically integrated and analyzed a series of J. curcas transcriptome data, which were used to generate JCDB. The database includes general gene information (including genomic coordinates and sequences), gene functional annotation (including gene ontology (GO), KEGG, Pfam, and InterPro), gene interaction networks (gene co-expression and protein-protein interaction (PPI) networks), and gene expression matrices. We also provide tools for browsing, searching, and downloading all data, as well as user-friendly web services such as BLAST, the JBrowse genome browser, ID conversion, heatmaps, and gene network analysis tools. In the case studies presented here, we demonstrate the possibility of using JCDB to mine genes related to flowering and lipid synthesis pathways in $J$. curcas. We believe that JCDB represents a valuable and unique resource for further functional genomics studies of J. curcas.

\section{Construction and content}

\section{Transcriptome data retrieving and processing}

To acquire comprehensive genomic information for $J$. curcas, we developed a pipeline for transcriptome data collection, integration, and novel gene identification, including non-coding RNAs (Fig. 1a). First, publicly available transcriptome data of $J$. curcas were downloaded from NCBI's Sequence Read Archive (SRA) database. Detailed information was collated for each sample, including experimental description, organizational information, and references. (Additional file 1). The SRA data was dumped into the FASTQ format using the fastqdump utility from the NCBI SRA Toolkit v.2.5.2 [33]. Raw reads were quality trimmed using Trimmomatic (version 0.32) with parameters "LEADING:20 TRAILING:20 MINLEN:36" [34]. Then, all clean reads were mapped onto the J. curcas genome (JatCur_1.0) [15] using TopHat 2 (version 2.1.0), with default parameters except maximum intron length, which was set to 20,000 bp [35]. Next, the mapped reads were assembled using Cufflinks (version 2.2.1) with the RefSeq genome as a guide, and a combined transcriptome assembly was generated using Cuffmerge [36]. Finally, genes that were identified by Cuffcompare as non-overlapping with known genes, having more than one exon, longer than $200 \mathrm{bp}$, and with FPKM (fragments per kilobase per million) greater than 0.1 were considered as novel gene candidates.

Novel protein-coding and non-coding gene identification As shown in Fig. 1a, novel transcript sequences were first used as query for a BLASTX search against the NCBI non-redundant protein (NR) database with default parameters. Then, open reading frames (ORFs) of these matches were identified using TransDecoder v4.1.0 (https://github.com/TransDecoder/TransDecoder).

Matches with a completed ORF were annotated as protein-coding genes. Non-coding genes were further identified using CPC (Version 0.9-r2) [37] and CNCI (Version 2) [38] among the genes not matching the NCBI NR database. The remaining genes were annotated as transcripts of unknown coding potential (TUCPs).

\section{Protein-coding and novel non-coding gene annotation}

All the protein-coding and novel non-coding genes in JCDB were annotated using the in-house gene annotation pipeline (Fig. 1b). For the annotation of proteincoding genes, Pfam [39] was used for protein domain and gene family analysis. GO annotations were assigned using InterProScan [40] and Blast2GO [41]. KEGG annotations were assigned using the online service KAAS [42]. For the annotation of novel non-coding genes, we downloaded all small non-coding RNA and long noncoding RNA (lncRNA) sequences from the plant ncRNA database PNRD [43] and annotated the JCDB novel non-coding genes using a BLAST search with default parameters. In total, there were 27 novel noncoding genes with BLAST hits to PNRD, including 22 microRNA (miRNA) host genes, two long intergenic non-coding RNAs (lincRNAs), and three lncRNAs of unknown type. 


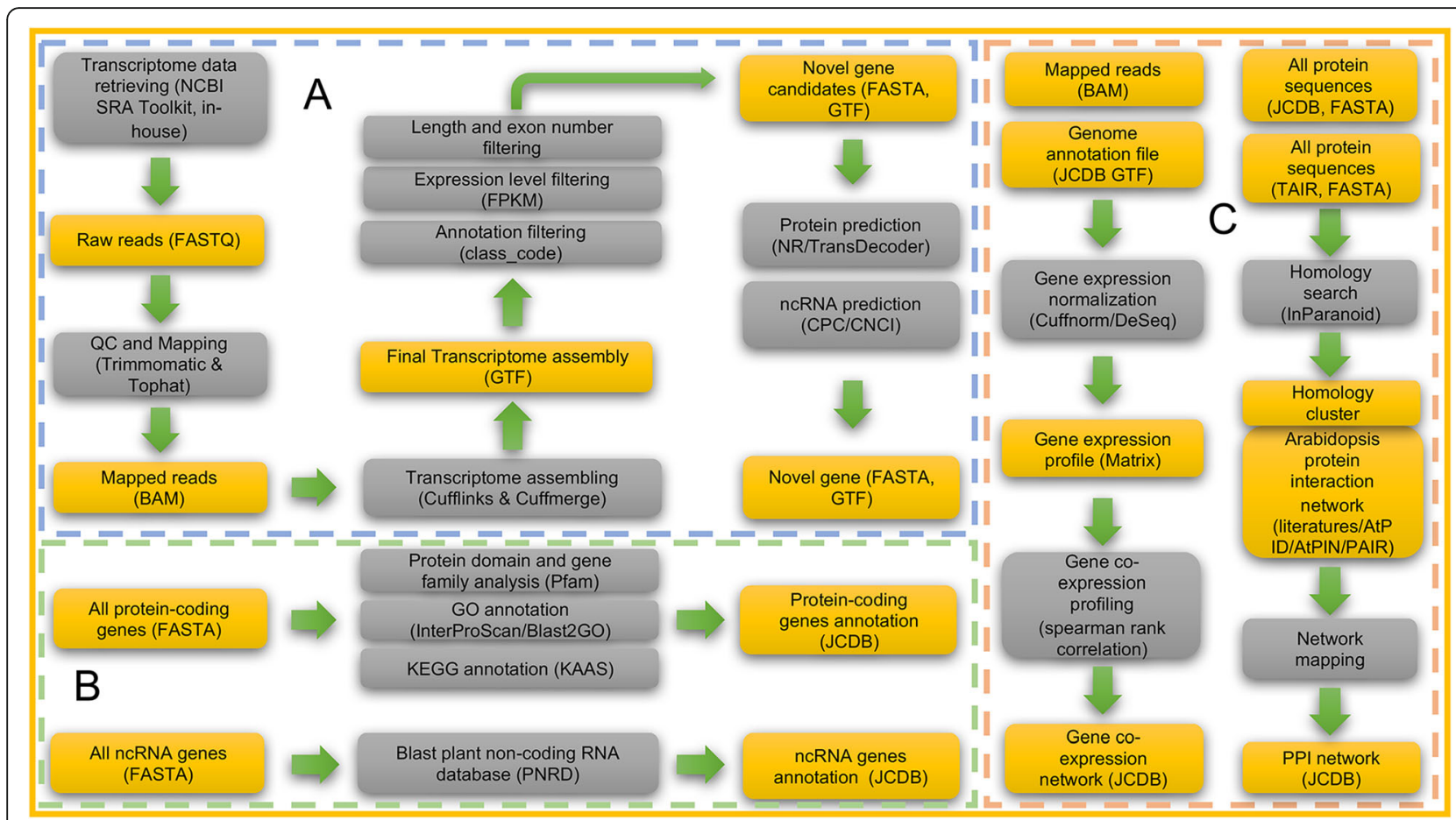

Fig. 1 JCDB pipelines for data retrieval and processing. a Novel gene discovery pipeline. b Coding and non-coding gene (ncRNA) annotation pipeline. c Gene co-expression and PPI network construction pipeline

\section{Co-expression network construction}

As shown in Fig. 1c, for conventional RNA-Seq data, gene expression profiles were identified and normalized using Cuffnorm [36]. For digital gene expression data, read count tables were created using htseq-count in the HTSeq toolkit [44] and then normalized using the DESeq method [45]. The two types of expression matrix were merged and normalized again using the upperquartile method [44]. A gene co-expression network was constructed using the Spearman's rank correlation coefficients of gene pairs across the samples. Gene pairs with correlation value higher than 0.6 and adjusted $P$-value less than 0.01 were regarded as showing co-expression.

\section{Protein-protein interaction network construction}

Arabidopsis protein interactions were collected from the literature [46-48] and from three databases (AtPID 5.0 [49], AtPIN 9.0 [50], and PAIR 3.0 [51]), giving a total of 18,037 Arabidopsis genes and 241,468 interactions. Arabidopsis protein sequences were downloaded from TAIR10 [52]. The pairwise similarity matching tool InParanoid [53] with default settings was used to find orthologous groups between the J. curcas and Arabidopsis proteomes. The $J$. curcas PPI network was inferred from the Arabidopsis PPI network [46-51] by homology mapping (Fig. 1c).

\section{System implementation}

The JCDB server was built using Apache/2.4.6 (CentOS), PHP (version 5.4.16), and relational database MySQL (version 5.5.48). The entity relationship diagram is provided in Additional file 2. The physical server was a 4 Intel(R) Xeon(R) CPU E5-2640 v3 @ $2.60 \mathrm{GHz}$ with 8 GB RAM. All data and information were stored in MySQL tables to facilitate efficient management, search, and display. A combination of Thinkphp (version 3.2), Bootstrap (version 3.3.7), and JQuery (version 3.3.7) were used to construct the website. The network was visualized using Cytoscape.js (version 3.8).

\section{Utility and discussion \\ Search JCDB}

The 'Search page of JCDB (Fig. 2a) provides three different types of search services. 'Keyword Search' uses keywords including gene types (such as protein_coding and ncRNA), gene symbols (such as bZIP, myb, and bHLH), and gene/transcript/protein IDs (such as JCDBG00001, JCDBR00001, and JCDBP00001) from JCDB or other databases (such as RefSeq, JAT_r4.5, and GenBank). 'Position Search' finds genes/transcripts/proteins located in one specific genomic region specified by the users. 'Network Search' provides a gene's direct network neighbors in the PPI or co-expression network. 
A
Keyword search
gene

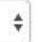
keywords
QSearch

You can use JCDB ID (e.g. JCDBG00001, JCDBR00001, JCDBP00001), Gene Symbol (e.g. myb, bHLH, bZIP), Gene type (e.g. protein_coding, ncRNA, ) or ID from other database as the keyword (e.g. YP_002720093.1, Jcr4U31230).

Position search

\begin{tabular}{|c|c|}
\hline gene & scafford:start:end \\
\hline
\end{tabular}

Search gene/transcript/protein which located on a specific chromosome region using scafford ID, start pos \& end pos (e.g. NC_012224.1:10-10000).

Network search

protein protein interaction

node1, eg. JCDBG00001

QSearch

B

Search one gene's direct network neighbors from protein interaction network or gene co-expression network using JCDB ID (e.g. JCDBG12184).

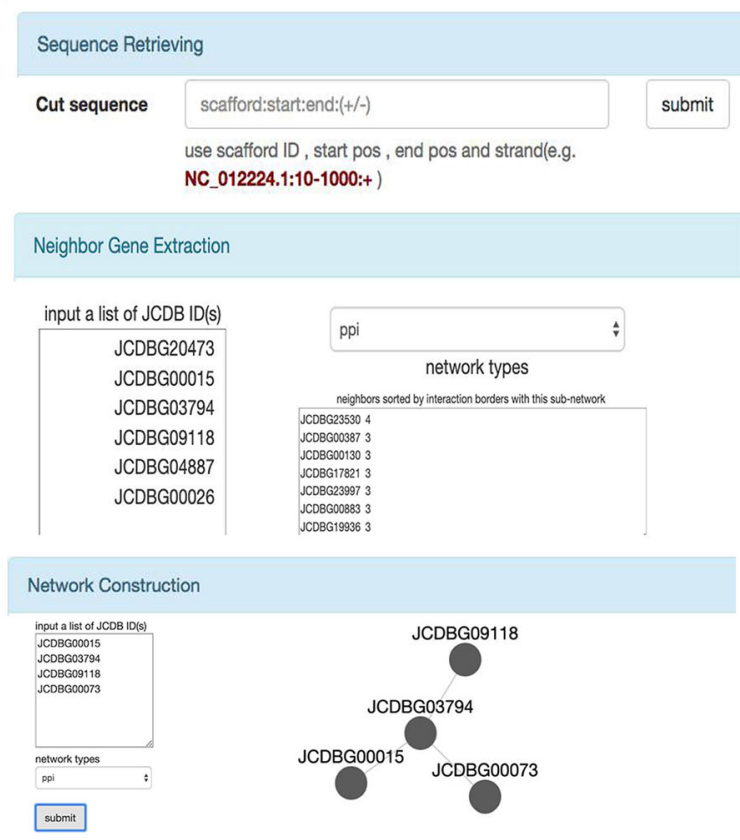

C
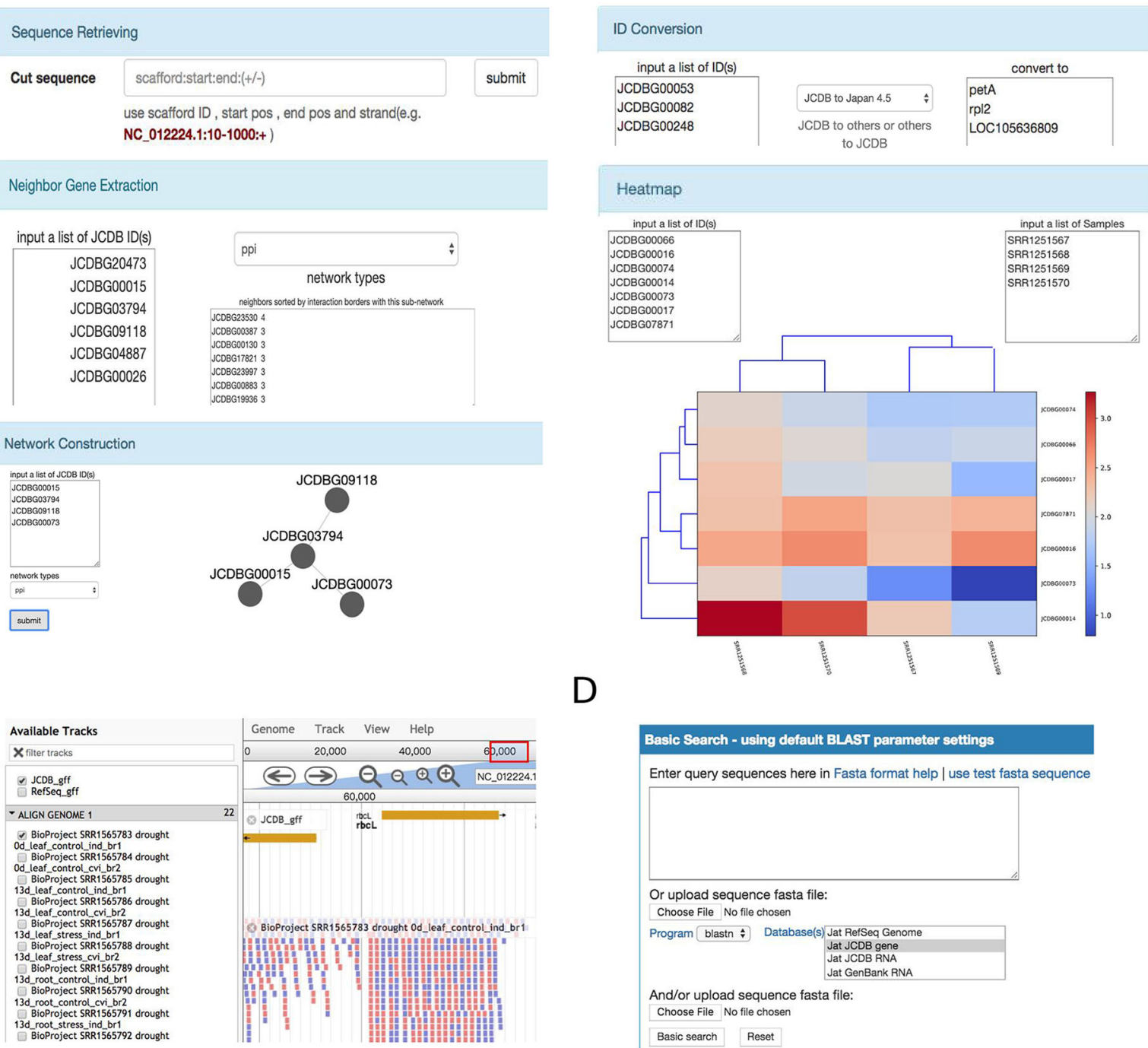

D

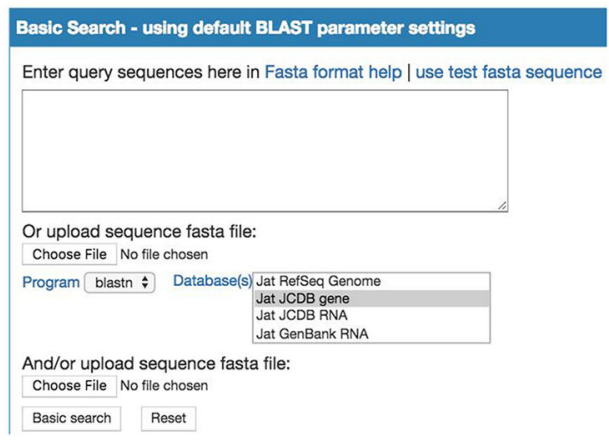

Fig. 2 Screenshots of the JCDB online tools. a Keyword search, position search, and network search. b JCDBtools, the web-based toolkit. c JBrowse, the genome browser. d Online BLAST search 


\section{JCDBTools}

JCDBTools is a web-based toolkit that provides five tools to help molecular biologists use JCDB more efficiently (Fig. 2b). 'Sequence Retrieving' can be used to retrieve genome sequences by providing genomic coordinates. 'ID Conversion' converts gene/transcript/protein IDs between JCDB and other databases (including RefSeq, JAT_r4.5, and GenBank). 'Heatmap' can be used to retrieve the gene expression patterns of a group of genes from different samples. 'Network Construction' can be used to extract a sub-network for user-specified genes from the global PPI or co-expression network. 'Neighbor Gene Extraction' can be used to extract the nearest neighbors of a sub-network in the global PPI or coexpression network.

\section{JBrowse}

JCDB integrates genome browser JBrowse [54] to provide easy-to-use panning and zooming navigation of the
J. curcas reference genome (Fig. 2c). JBrowse includes various tracks, such as the J. curcas genome sequence, gene annotation GFF files from JCDB and RefSeq, and transcriptome-aligned BAM files for different samples.

\section{BLAST service}

The BLAST server (Fig. 2d) was implemented using ViroBLAST [55], which is a user-friendly tool for interfacing with the command-line NCBI BLAST+ toolkits. For user convenience, JCDB BLAST provides nucleotide databases (RefSeq genome/RNA, JCDB gene/RNA, and GenBank RNA/CDS) and protein databases (JCDB Protein, GenBank Protein, and RefSeq Protein).

\section{Browse JCDB}

Users can browse all JCDB genes directly on the 'Browse' page (Fig. 3a), which provides basic annotations for each gene, such as gene name, gene type, and genomic location. Users can also select and download FASTA files for

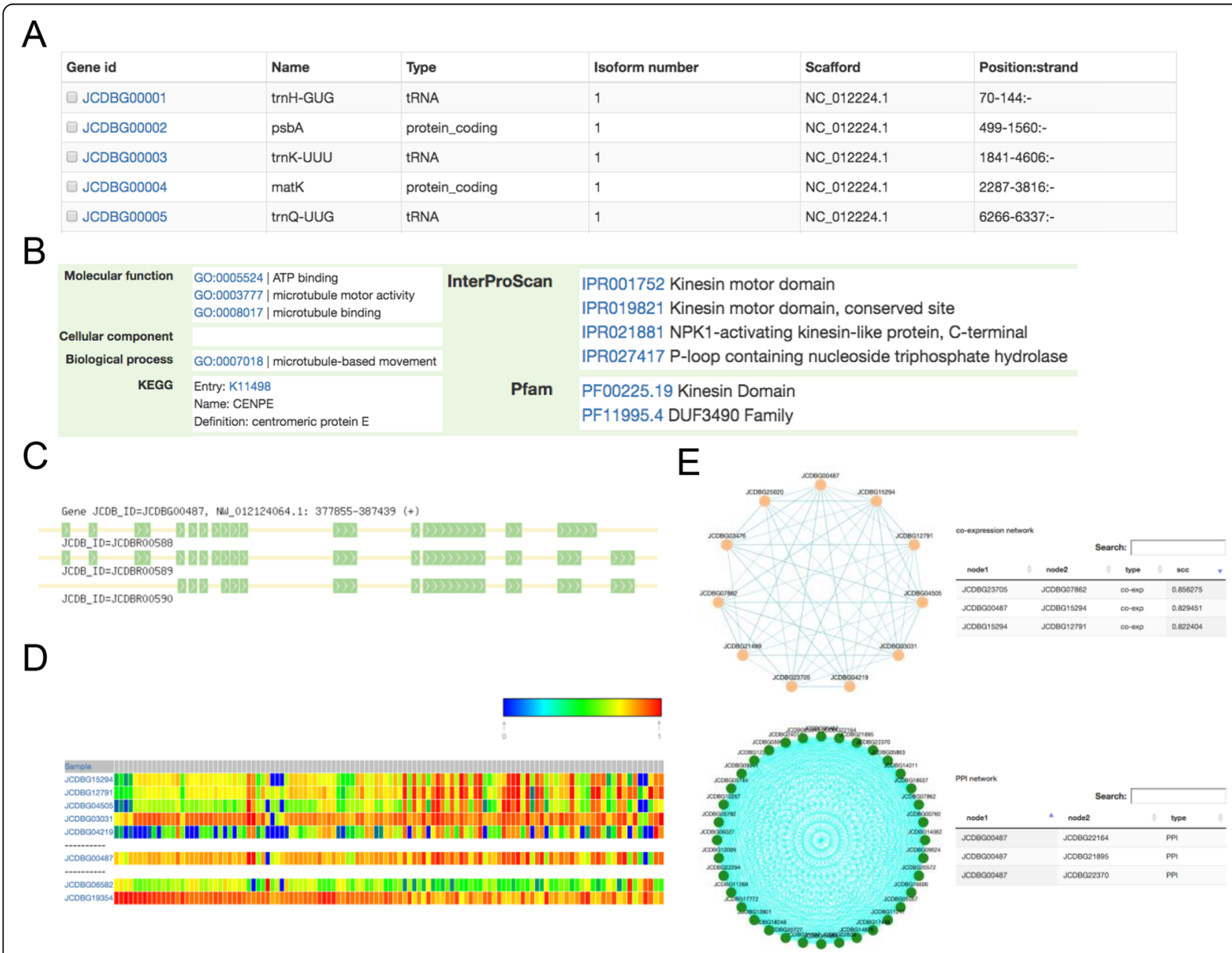

Fig. 3 Screenshots of the browse and detail information pages. a The Browse page. b Detailed gene functional annotations. c Gene structural information. d Gene expression heatmap. e Gene co-expression network and PPI network 
genes if required. Detailed information page for a specific gene can be accessed by clicking on the gene ID. For each gene, JCDB aims to provide as much comprehensive information as possible, including detailed GO, KEGG, InterPro, and Pfam functional annotations (Fig. 3b); structural information for each gene isoform (Fig. 3c); gene expression heatmaps (Fig. 3d); and coexpression and PPI sub-networks (Fig. 3e). In the gene expression heatmap panel, users can select the number of co-expressed genes that they want to display. In the gene sub-network panel, users can click and drag each gene node to move it, or click each gene ID to redirect to its detail page. The network is also displayed as a table on the right-hand side with a search function. Users can sort the table by column.

\section{Database statistics}

Statistics for JCDB are summarized in Table 1. The current database release contains a total of 25,297 genes and 33,785 transcripts, including protein-coding genes $(22,446$, about $89 \%)$, non-coding genes (2391, about $9 \%)$, and TUCP genes (460, about $2 \%$ ). Compared with existing $J$. curcas databases $[13,15,32]$, JCDB includes more non-coding genes and more annotation information, as well as unique gene networks and expression profiles (Table 2). In JCDB, about 58, 40, and $74 \%$ of genes have GO, KEGG, and Pfam annotations, respectively; there are also about $90 \%$ genes in the co-expression network, $38 \%$ genes in the PPI network, and 114 expression profiles for 25,297 genes. Users can freely download all the above annotation files via the Download page.

\section{Case studies}

JCDB provides a comprehensive platform for J. curcas functional genomics research by integrating information

Table 1 Gene statistics and data integrated in JCDB

\begin{tabular}{ll}
\hline Category & Number \\
\hline Genes/transcripts & \\
All & $25,297 / 33,785$ \\
Protein-coding & $22,446(89 \%)$ \\
Non-coding & $2391(9 \%)$ \\
TUCP & $460(2 \%)$ \\
Gene annotation & \\
Gene ontology & $14,714(58 \%)$ \\
KEGG pathway & $10,217(40 \%)$ \\
Pfam domain & $18,829(74 \%)$ \\
Genes in network & \\
Co-expression network & $22,749(90 \%)$ \\
PPI network & $9602(38 \%)$ \\
Expression profiles & 114 \\
\hline
\end{tabular}

from various sources, including gene functional annotations and gene interaction networks, and various tools including BLAST search and gene network analysis. Here, we demonstrate the use of the information and tools provided by JCDB to mine some important gene pathways in J. curcas.

In order to better understand the genetic control of fatty acid and lipid biosynthesis in J. curcas, we collected 132 oil-related genes from Arabidopsis and identified oil-related gene candidates in J. curcas using the JCDB BLAST search. Using the 'Network Construction' function in JCDBTools, we obtained a J. curcas oilrelated gene sub-network, which showed that these $J$. curcas oil-related genes were closely connected (Fig. 4a). We also used the 'Neighbor Gene Extraction' function in JCDBTools to find J. curcas-specific oil-related genes. We first extracted all the nearest neighbors of the known oil-related genes and then retained those that interacted with known oil-related genes in both the PPI and co-expression networks. We examined the GO annotations of these $J$. curcas specific oil-related gene candidates using GOATOOLS [56] (Fig. 4b). Consistent with our assumption, these genes appeared to be related to oil synthesis. The top enriched GO terms for biological process (BP) included biosynthetic process, small molecule metabolic process, and oxoacid and carboxylic acid metabolic process; the top cellular component $(\mathrm{CC})$ term was macromolecular complex; and the top molecular function (MF) terms were ligase activity, transferase activity, transferring acyl groups, and catalytic activity.

We also investigated the flowering-related pathway in $J$. curcas. By manually reviewing the published literature, we identified 303 flowering-related genes of Arabidopsis. Then, using the same method, a total of 187 flowering-related genes in J. curcas were identified through homologous search, and the nearest neighbors and sub-network of these known floweringrelated genes were also obtained. In the sub-network, the J. curcas-specific flowering-related gene candidates were closely connected with the known floweringrelated genes. All the top 10 candidates had more than 25 interactions, including JCDBG05506 (Fig. 4c). Searching for this gene in JCDB revealed that JCDBG05506 is a MADS-box protein, with annotations including "FLOWERING LOCUS C" and "transcription factor". Furthermore, we counted the protein domain annotations of the top $50 \mathrm{~J}$. curcas-specific flowering-related gene candidates and found eight genes containing a homeobox domain, as well as two genes containing the zinc finger PHD-type domain and two genes containing the MADS-box domain (Fig. 4d). All of these protein domains are reported to be related to flowering [56-58]. 
Table 2 Comparison of gene annotations in JCDB with other Jatropha databases

\begin{tabular}{|c|c|c|c|c|c|c|c|}
\hline Database & Protein & ncRNA & $\mathrm{GO}$ & KEGG & Pfam & Network & Expression \\
\hline JAT_r4.5 [13] & 30,203 & 0 & $x$ & $x$ & $x$ & $x$ & $x$ \\
\hline KaPPA-View4 -Jatropha [32] & 40,929 & 0 & $x$ & $\sqrt{ }$ & $x$ & $\sqrt{ }$ & $\sqrt{ }$ \\
\hline RefSeq [15] & 21,574 & 2013 & $x$ & $x$ & $x$ & $x$ & $x$ \\
\hline$J C D B$ & 22,446 & 2391 & $\sqrt{ }$ & $\sqrt{ }$ & $\sqrt{ }$ & $\sqrt{ }$ & $\sqrt{ }$ \\
\hline
\end{tabular}

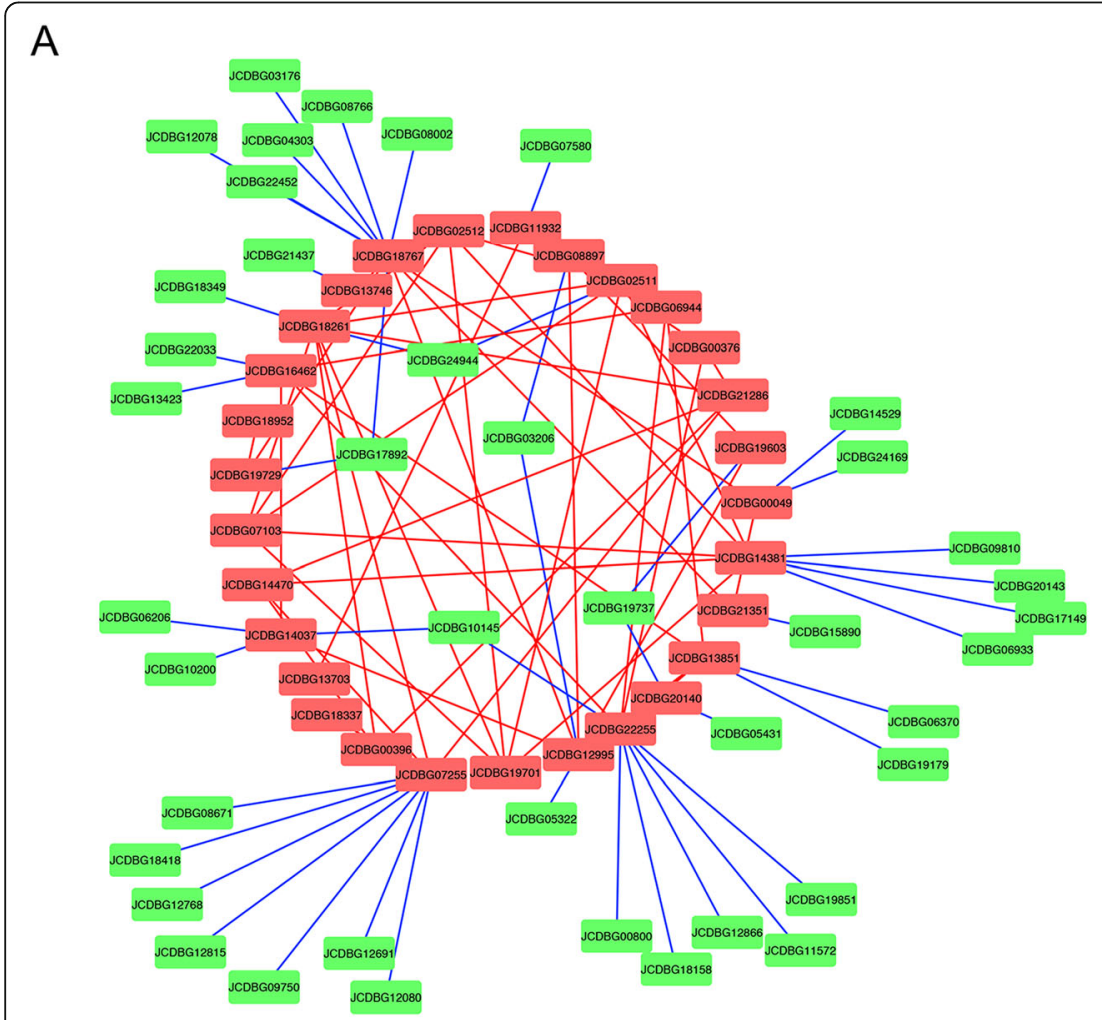

C

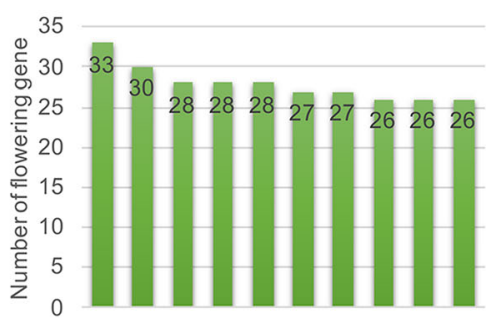

B

biosynthetic process small molecule metabolic process nitrogen compound metabolic process single-organism metabolic process oxoacid metabolic process carboxylic acid metabolic process macromolecular complex ligase activity transferase activity, transferring acyl groups catalytic activity

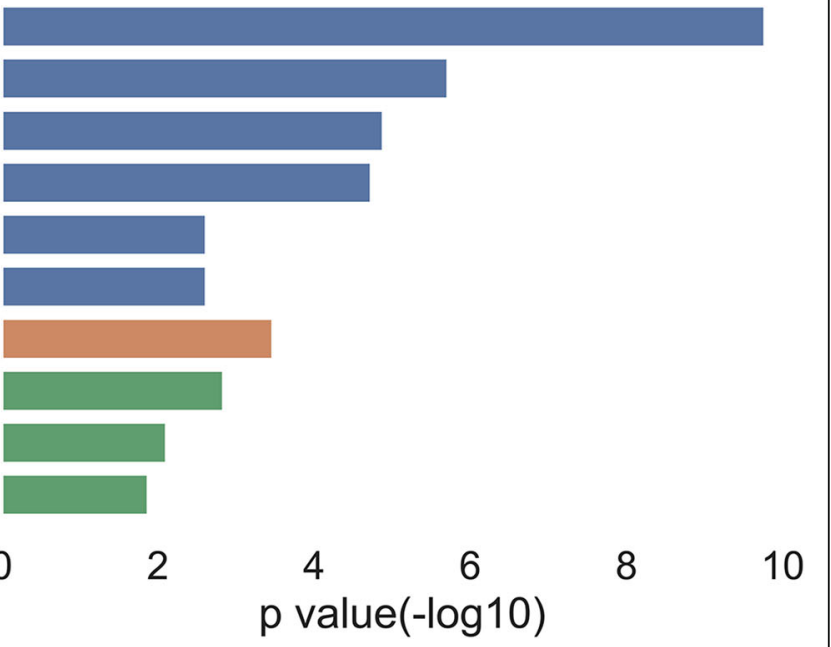

Fig. 4 Case studies: gene function prediction using JCDBTools. a Sub-network of oil-related genes in J. curcas (red: known, green: prediction). b GO enrichment analysis of predicted oil-related genes (blue: BP, orange: CC, green: MF). c Numbers of known flowering-related genes interacting with predicted flowering-related genes (top 10). d Protein domain information for the top 50 predicted flowering-related genes 


\section{Conclusions}

The plant J. curcas has attracted much attention worldwide owing to its potential for biofuel production. However, current databases for J. curcas did not effectively integrate multiple data sources and lacked useful tools for data presentation and analysis, and thus could not meet the needs of functional genomics study. For these reasons, we built JCDB, an integrated knowledge base, which includes not only basic gene information but also gene functional annotations, gene expression profiles, and gene network information. JCDB also provides a user-friendly platform for data presentation and analysis, offering a variety of tools including BLAST, the JBrowse genome browser, and JCDBTools. JCDB is the most comprehensive and well-annotated database available for J. curcas functional genomics research. Future work will include developing new tools to assist users with indepth exploration of JCDB. We believe JCDB will continue to provide a valuable and unique resource for $J$. curcas functional genomics studies.

\section{Supplementary information}

Supplementary information accompanies this paper at https://doi.org/10. 1186/s12864-019-6356-z.

Additional file 1. The transcriptome data sources of Jatropha curcas.

Additional file 2. The entity relationship diagram of JCDB.

\section{Abbreviations}

BP: Biological process; CC: Cellular component; GO: Gene ontology; JCDB: Jatropha curcas database; KEGG: Kyoto Encyclopedia of Genes and Genomes; IncRNA: Long non-coding RNA; MF: Molecular function; ORFs: Open reading frames; PPI: Protein-protein interaction; SRA: Sequence Read Archive; TUCPs: Transcripts of unknown coding potential

\section{Acknowledgments}

Data analysis was supported by the HPC Platform, The Public Technology Service Center of XTBG, CAS, China.

\section{About this supplement}

This article has been published as part of BMC Genomics, Volume 20 Supplement 9, 2019: 18th International Conference on Bioinformatics. The full contents of the supplement are available at https://bmcgenomics. biomedcentral.com/articles/supplements/volume-20-supplement-9.

\section{Authors' contributions}

$\mathrm{CL}$ and ZX conceived, designed, and supervised this study. XZ, BP, and MC collected and compiled data from the literature and from public databases. $X Z$, WC, and $J \mathrm{~L}$ designed and developed the database. $X Z$, $J$, and $C L$ prepared the draft of the manuscript. All authors reviewed, edited, and approved the manuscript.

\section{Funding}

Publication of this supplement was funded by the National Natural Science Foundation of China (No. 31970609, 31670612, 31870291 and 31370595), a Start-up Fund from Xishuangbanna Tropical Botanical Garden (XTBG), the Programme of the Chinese Academy of Sciences (kfj-brsn-2018-6-008 and 2017XTBG-T02) and the 'Top Talents Program in Science and Technology' of Yunnan Province.

\section{Availability of data and materials}

All data generated or analyzed during this study are included in this published article.
Ethics approval and consent to participate

Not applicable.

\section{Consent for publication}

Not applicable.

\section{Competing interests}

The authors declare that they have no competing interests.

\section{Author details}

${ }^{1}$ CAS Key Laboratory of Tropical Plant Resources and Sustainable Use, Xishuangbanna Tropical Botanical Garden, The Innovative Academy of Seed Design, Chinese Academy of Sciences, Menglun, Mengla, Yunnan 666303,

China. ${ }^{2}$ College of Life Sciences, University of Chinese Academy of Sciences, Beijing 100049, China. ${ }^{3}$ Center of Economic Botany, Core Botanical Gardens, Chinese Academy of Sciences, Menglun, Mengla, Yunnan 666303, China.

Received: 2 November 2019 Accepted: 29 November 2019

Published: 24 December 2019

\section{References}

1. Mazumdar P, Singh P, Babu S, Siva R, Harikrishna JA. An update on biological advancement of Jatropha curcas L.: new insight and challenges. Renew Sust Energ Rev. 2018;91:903-17.

2. Giwa A, Adeyemi I, Dindi A, Lopez CG-B, Lopresto CG, Curcio S, Chakraborty $\mathrm{S}$. Techno-economic assessment of the sustainability of an integrated biorefinery from microalgae and Jatropha: a review and case study. Renew Sust Energ Rev. 2018;88:239-57.

3. Laviola BG, Rodrigues EV, Teodoro PE, Peixoto LA, Bhering LL. Biometric and biotechnology strategies in Jatropha genetic breeding for biodiesel production. Renew Sust Energ Rev. 2017;76:894-904.

4. Moniruzzaman M, Yaakob Z, Khatun R. Biotechnology for Jatropha improvement: a worthy exploration. Renew Sust Energ Rev. 2016;54: 1262-77.

5. Montes JM, Melchinger AE. Domestication and breeding of Jatropha curcas L. Trends Plant Sci. 2016:21(12):1045-57.

6. Abdelgadir HA, Van Staden J. Ethnobotany, ethnopharmacology and toxicity of Jatropha curcas L. (Euphorbiaceae): a review. S Afr J Bot. 2013;88:204-18

7. Maghuly F, Laimer M. Jatropha curcas, a biofuel crop: functional genomics for understanding metabolic pathways and genetic improvement. Biotechnol J. 2013;8(10):1172-82.

8. King AJ, He W, Cuevas JA, Freudenberger M, Ramiaramanana D, Graham IA. Potential of Jatropha curcas as a source of renewable oil and animal feed. J Exp Bot. 2009;60(10):2897-905.

9. Islam AKMA, Yaakob Z, Anuar N. Jatropha: a multipurpose plant with considerable potential for the tropics. Sci Res Essays. 2011;6(13):2597-605.

10. Ong HC, Mahlia TMI, Masjuki HH, Norhasyima RS. Comparison of palm oil, Jatropha curcas and Calophyllum inophyllum for biodiesel: a review. Renew Sust Energ Rev. 2011;15(8):3501-15.

11. Kumar A, Sharma S. An evaluation of multipurpose oil seed crop for industrial uses (Jatropha curcas L.): a review. Ind Crop Prod. 2008;28(1):1-10.

12. Carvalho CR, Clarindo WR, Praça MM, Araújo FS, Carels N. Genome size, base composition and karyotype of Jatropha curcas L., an important biofuel plant. Plant Sci. 2008;174(6):613-7.

13. Sato S, Hirakawa H, Isobe S, Fukai E, Watanabe A, Kato M, Kawashima K, Minami C, Muraki A, Nakazaki N, et al. Sequence analysis of the genome of an oil-bearing tree, Jatropha curcas L. DNA Res. 2011;18(1):65-76.

14. Hirakawa H, Tsuchimoto S, Sakai H, Nakayama S, Fujishiro T, Kishida Y, Kohara M, Watanabe A, Yamada M, Aizu T, et al. Upgraded genomic information of Jatropha curcas L. Plant Biotechnol. 2012;29(2):123-30.

15. Wu P, Zhou C, Cheng S, Wu Z, Lu W, Han J, Chen Y, Chen Y, Ni P, Wang Y, et al. Integrated genome sequence and linkage map of physic nut (Jatropha curcas L.), a biodiesel plant. Plant J. 2015;81(5):810-21.

16. Ha J, Shim S, Lee T, Kang YJ, Hwang WJ, Jeong H, Laosatit K, Lee J, Kim SK, Satyawan D, et al. Genome sequence of Jatropha curcas L., a non-edible biodiesel plant, provides a resource to improve seed-related traits. Plant Biotechnol J. 2019;17(2):517-30.

17. Kancharla N, Jalali S, Narasimham JV, Nair V, Yepuri V, Thakkar B, Reddy VB, Kuriakose B, N, S A M. De Novo Sequencing and Hybrid Assembly of the 
Biofuel Crop Jatropha curcas L.: Identification of Quantitative Trait Loci for Geminivirus Resistance. Genes (Basel). 2019;10(1):96.

18. Qin X, Zheng X, Huang X, Lii Y, Shao C, XU Y, Chen F. A novel transcription factor JcNAC1 response to stress in new model woody plant Jatropha curcas. Planta. 2014;239(2):511-20.

19. Ma Y, Yin Z, Ye J. Lipid biosynthesis and regulation in Jatropha, an emerging model for woody energy plants; 2017. p. 113-27.

20. Tsuchimoto S, editor. The Jatropha genome: Volume 1st ed. 2017. Osaka University: Springer Japan; 2017.

21. Fresnedo-Ramirez J. The floral biology of Jatropha curcas L.-a review. Trop Plant Biol. 2013;6(1):1-15.

22. Chen MS, Pan BZ, Fu Q, Tao YB, Martinez-Herrera J, Niu L, Ni J, Dong Y, Zhao ML, Xu ZF. Comparative transcriptome analysis between gynoecious and monoecious plants identifies regulatory networks controlling sex determination in Jatropha curcas. Front Plant Sci. 2016;7: 1953.

23. Jiang $H$, Wu P, Zhang S, Song $C$, Chen $Y$, Li M, Jia Y, Fang X, Chen F, Wu G Global analysis of gene expression profiles in developing physic nut (Jatropha curcas L.) seeds. PLoS One. 2012;7(5):e36522.

24. Wang H, Zou Z, Wang S, Gong M. Global analysis of transcriptome responses and gene expression profiles to cold stress of Jatropha curcas L. PLoS One. 2013;8(12):e82817.

25. Juntawong P, Sirikhachornkit A, Pimjan R, Sonthirod C, Sangsrakru D, Yoocha T, Tangphatsornruang S, Srinives P. Elucidation of the molecular responses to waterlogging in Jatropha roots by transcriptome profiling. Front Plant Sci. 2014;5:658.

26. Zhang L, Zhang C, Wu P, Chen Y, Li M, Jiang H, Wu G. Global analysis of gene expression profiles in physic nut (Jatropha curcas L.) seedlings exposed to salt stress. PLoS One. 2014;9(5):e97878.

27. Zhang C, Zhang L, Zhang S, Zhu S, Wu P, Chen Y, Li M, Jiang H, Wu G. Global analysis of gene expression profiles in physic nut (Jatropha curcas L.) seedlings exposed to drought stress. BMC Plant Biol. 2015;15:17.

28. Sapeta H, Lourenco T, Lorenz S, Grumaz C, Kirstahler P, Barros PM, Costa JM, Sohn K, Oliveira MM. Transcriptomics and physiological analyses reveal coordinated alteration of metabolic pathways in Jatropha curcas drought tolerance. J Exp Bot. 2016;67(3):845-60.

29. Ni J, Gao C, Chen MS, Pan BZ, Ye K, Xu ZF. Gibberellin promotes shoot branching in the perennial woody plant Jatropha curcas. Plant Cell Physiol. 2015;56(8):1655-66.

30. Pan BZ, Chen MS, Ni J, Xu ZF. Transcriptome of the inflorescence meristems of the biofuel plant Jatropha curcas treated with cytokinin. BMC Genomics. 2014;15:974.

31. Yang M, Wu Y, Jin S, Hou J, Mao Y, Liu W, Shen Y, Wu L. Flower bud transcriptome analysis of Sapium sebiferum (Linn.) Roxb. and primary investigation of drought induced flowering: pathway construction and Gquadruplex prediction based on transcriptome. PLoS One. 2015;10(3): e0118479.

32. Sakurai N, Ogata Y, Ara T, Sano R, Akimoto N, Hiruta A, Suzuki H, Kajikawa M, Widyastuti U, Suharsono S, et al. Development of KaPPA-View4 for omics studies on Jatropha and a database system KaPPA-loader for construction of local omics databases. Plant Biotechnol. 2012;29(2):131-5.

33. Leinonen $R$, Sugawara $H$, Shumway M. International nucleotide sequence database C: the sequence read archive. Nucleic Acids Res. 2011;39(Database issue):D19-21

34. Bolger AM, Lohse M, Usadel B. Trimmomatic: a flexible trimmer for Illumina sequence data. Bioinformatics. 2014;30(15):2114-20.

35. Kim D, Pertea G, Trapnell C, Pimentel H, Kelley R, Salzberg SL. TopHat2: accurate alignment of transcriptomes in the presence of insertions, deletions and gene fusions. Genome Biol. 2013;14(4):R36.

36. Trapnell C, Williams BA, Pertea G, Mortazavi A, Kwan G, van Baren MJ, Salzberg SL, Wold BJ, Pachter L. Transcript assembly and quantification by RNA-Seq reveals unannotated transcripts and isoform switching during cell differentiation. Nat Biotechnol. 2010; 28(5):511-5.

37. Kong L, Zhang Y, Ye ZQ, Liu XQ, Zhao SQ, Wei L, Gao G. CPC: assess the protein-coding potential of transcripts using sequence features and support vector machine. Nucleic Acids Res. 2007;35(Web Server issue): W345-9.

38. Sun L, Luo H, Bu D, Zhao G, Yu K, Zhang C, Liu Y, Chen R, Zhao Y. Utilizing sequence intrinsic composition to classify protein-coding and long noncoding transcripts. Nucleic Acids Res. 2013;41(17):e166.
39. Finn RD, Bateman A, Clements J, Coggill P, Eberhardt RY, Eddy SR, Heger A, Hetherington K, Holm L, Mistry J, et al. Pfam: the protein families database. Nucleic Acids Res. 2014;42(Database issue):D222-30.

40. Jones P, Binns D, Chang HY, Fraser M, Li W, McAnulla C, McWilliam H, Maslen J, Mitchell A, Nuka G, et al. InterProScan 5: genome-scale protein function classification. Bioinformatics. 2014;30(9):1236-40.

41. Conesa A, Gotz S, Garcia-Gomez JM, Terol J, Talon M, Robles M. Blast2GO: a universal tool for annotation, visualization and analysis in functional genomics research. Bioinformatics. 2005;21(18):3674-6.

42. Moriya Y, Itoh M, Okuda S, Yoshizawa AC, Kanehisa M. KAAS: an automatic genome annotation and pathway reconstruction server. Nucleic Acids Res. 2007;35(Web Server issue):W182-5.

43. Yi X, Zhang Z, Ling Y, Xu W, Su Z. PNRD: a plant non-coding RNA database. Nucleic Acids Res. 2015;43(Database issue):D982-9.

44. Bullard JH, Purdom E, Hansen KD, Dudoit S. Evaluation of statistical methods for normalization and differential expression in mRNA-Seq experiments. BMC Bioinformatics. 2010;11:94.

45. Anders S, Huber W. Differential expression analysis for sequence count data. Genome Biol. 2010:11(10):R106.

46. Arabidopsis Interactome Mapping C. Evidence for network evolution in an Arabidopsis interactome map. Science. 2011;333(6042):601-7.

47. Mukhtar MS, Carvunis AR, Dreze M, Epple P, Steinbrenner J, Moore J, Tasan M, Galli M, Hao T, Nishimura MT, et al. Independently evolved virulence effectors converge onto hubs in a plant immune system network. Science. 2011;333(6042):596-601

48. Jones AM, Xuan Y, Xu M, Wang RS, Ho CH, Lalonde S, You CH, Sardi MI, Parsa SA, Smith-Valle E, et al. Border control--a membrane-linked interactome of Arabidopsis. Science. 2014;344(6185):711-6.

49. Li P, Zang W, Li Y, Xu F, Wang J, Shi T. AtPID: the overall hierarchical functional protein interaction network interface and analytic platform for Arabidopsis. Nucleic Acids Res. 2011;39(Database issue):D1130-3.

50. Brandao MM, Dantas LL, Silva-Filho MC. AtPIN: Arabidopsis thaliana protein interaction network. BMC Bioinformatics. 2009:10:454

51. Lin $M$, Shen X, Chen X. PAIR: the predicted Arabidopsis interactome resource. Nucleic Acids Res. 2011:39(Database issue):D1134-40.

52. Poole RL. The TAIR database. Methods Mol Biol. 2007;406:179-212

53. Ostlund G, Schmitt T, Forslund K, Kostler T, Messina DN, Roopra S, Frings O, Sonnhammer EL. InParanoid 7: new algorithms and tools for eukaryotic orthology analysis. Nucleic Acids Res. 2010;38(Database issue):D196-203.

54. Buels R, Yao E, Diesh CM, Hayes RD, Munoz-Torres M, Helt G, Goodstein DM, Elsik CG, Lewis SE, Stein L, et al. JBrowse: a dynamic web platform for genome visualization and analysis. Genome Biol. 2016;17:66.

55. Deng W, Nickle DC, Learn GH, Maust B, Mullins JI. ViroBLAST: a stand-alone BLAST web server for flexible queries of multiple databases and user's datasets. Bioinformatics. 2007;23(17):2334-6.

56. Heijmans K, Morel P, Vandenbussche M. MADS-box genes and floral development: the dark side. J Exp Bot. 2012;63(15):5397-404.

57. Matsumoto N, Okada K. A homeobox gene, PRESSED FLOWER, regulates lateral axis-dependent development of Arabidopsis flowers. Genes Dev. 2001:15(24):3355-64.

58. Yokoyama Y, Kobayashi S, Kidou S-i. PHD type zinc finger protein PFP represses flowering by modulating FLC expression in Arabidopsis thaliana. Plant Growth Regul. 2019;88:49.

\section{Publisher's Note}

Springer Nature remains neutral with regard to jurisdictional claims in published maps and institutional affiliations.

\section{Ready to submit your research? Choose BMC and benefit from:}

- fast, convenient online submission

- thorough peer review by experienced researchers in your field

- rapid publication on acceptance

- support for research data, including large and complex data types

- gold Open Access which fosters wider collaboration and increased citations

- maximum visibility for your research: over $100 \mathrm{M}$ website views per year

At $\mathrm{BMC}$, research is always in progress.

Learn more biomedcentral.com/submissions 